\title{
Surgical Experience with Pediatric Pulmonary Hydatid Cysts
}

Rajbhandary GL

Dr Gambhir Lal Rajbhandary, Prof. of CTVS (NAMS), Shree Birendra Hospital

\section{Introduction}

Like in many agriculture farming countries Cystic Echinococcal disease is Endemic in Nepal also $0^{1,2}$. Incidence of liver \& pulmonary hydatid cysts are common among adult population in Nepal, but there are few literature published on surgical experience with pulmonary hydatid cyst in pediatric age group in $\mathrm{Nepal}^{3}$.

\section{Material}

During last 14 years since 1994 to 2008, 18 cases of pulmonary hydatid cyst were operated at Cardio-thoracic surgery unit of Birendra Hospital. There were 14 male $\& 4$ female. Their age range from 7 years to 70 years. There were 2 patients between 7 years to 14 years. Recently there were more presentation of hydatid cyst in young age group.

\section{Case no 1 (Operated 2008 )}

\section{Pediatric case No 1}

A 14 years old boy presented with Rt sided chest pain, cough \& fever one month, X-ray chest showed huge round Radio Opaque shadow over $R t$ lung. $C T$ scan of chest reveled Cystic homogenous opacity - Rt lung Lung Cyst on Rt. lower lobe size $-12 \mathrm{~cm} \times 10 \mathrm{~cm}$ $P$ t had Pre-Operative, Tab. Albendazole $400 \mathrm{mg} \mathrm{BD}$ for 4 weeks 4,5 .Operation:- Rt Thoracotomy $\&$ enucleation of hydatid cyst from Rt lower lobe ${ }^{6,7}$. The bronchi at opening were closed with Proline suture. The cavity is closed with Vicryl suture Post operation period was smooth. Patient had unilocator hydatid cyst $\&$ on microscopic examination histopathology confirmed Echinococcal pathology.

\section{Case no 2. Operated 2008 AD}

\section{Pediatric case No. 2}

A 7 years old boy presented with cough, fever, Hemoptysis - 2 months on x-ray chest there were two large rounds opacities over Rt lung one Upper lobe \& one is $\mathrm{Rt}$ lower lobe lung.

CT scan of chest revealed Cyst Size $-10 \mathrm{~cm} \times 8 \mathrm{~cm}$ on Rt Lung Lower lobe. Cyst Size $-8 \mathrm{~cm} \times 6 \mathrm{~cm}$ on Rt lung upper lobe. On USG abdomen there was no hepatic cyst. Blood agglutinate test for Ecchinococcus was Negative. P tatient was operated after 4 weeks of Albendazole $400 \mathrm{mg}$ daily. During surgery there was large unilocator cyst over Rt lower lobe lung

Cyst of Rt. Lobe was enucleated, Cavity closed multiple layers. Another lung cyst on Rt upper lobe was also enucleated \& cavity obliterated, Pt had smooth post overactive recovery. Fig 1,2,3,4 shows the patient during and post operation.

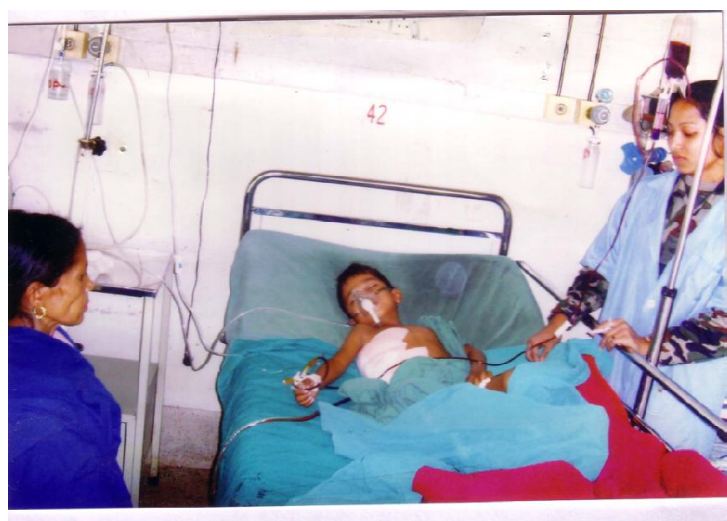

Fig. 1

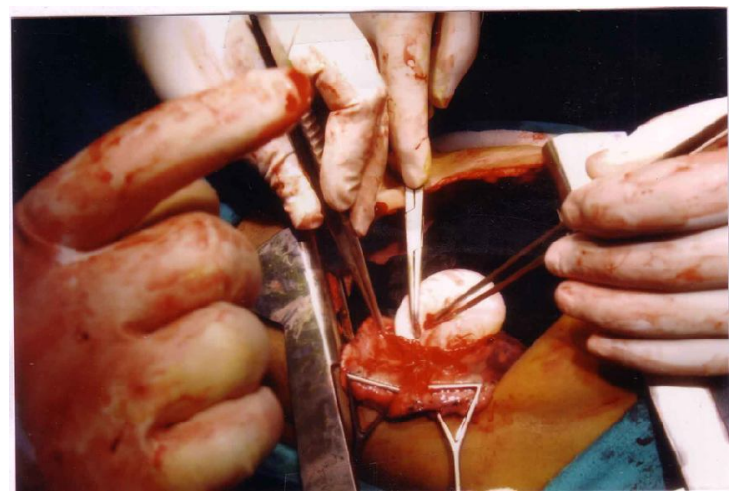

Fig. 2

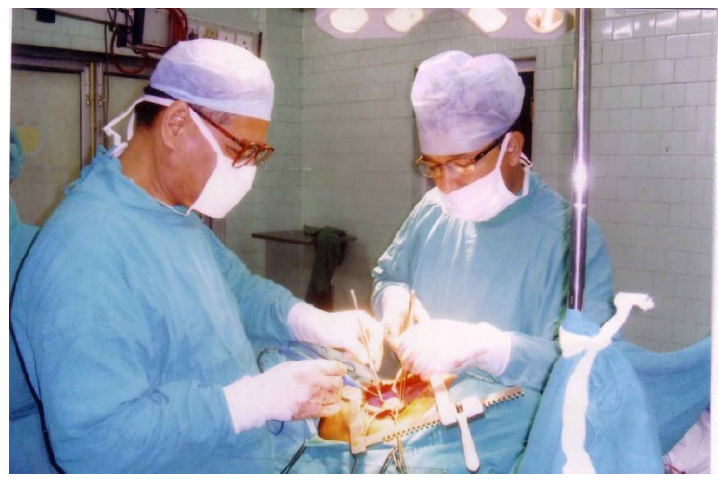

Fig. 3

Address for correspondence: gambhirlrb@ hotmail.com 


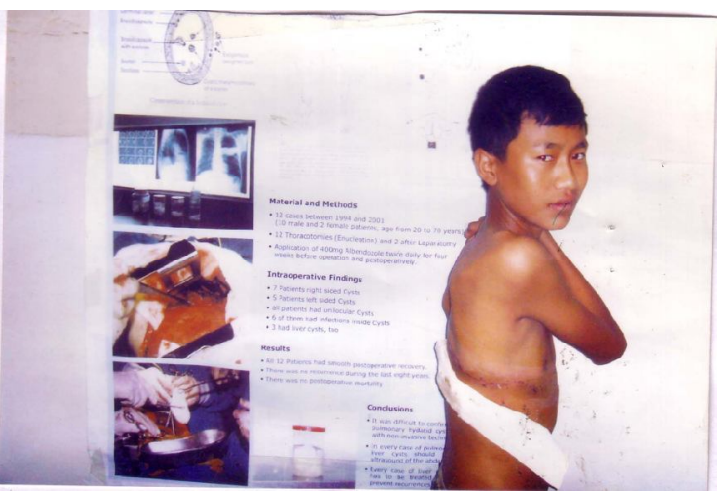

Fig. 4

\section{Discussion}

Cystic hydatid cyst of lung $\&$ liver are common in adult age group in Nepal.

There were not many cases presented with hydatid cyst in Pediatric age group in Nepal.

Recently we have noticed increase in pulmonary hydatid cyst in young age group in Nepal.

Most of the cyst in our country present as Unilocator Cysts but size were large 7,8 .

Both the Pediatric pulmonary hydatid cysts fall in WHO group 1 larger than $2 \mathrm{~cm}$. \& active ${ }^{9}$.

- All the patients had smooth post operative recovery $\&$ there was no reporting of recurrence in 14 years of follow up ${ }^{10}$.

VATS surgery was not used due to large size of Pulmonary Cyst $\&$ to avoid rupture $\&$ recurrence ${ }^{11}$.

\section{Conclusion}

Pulmonary hydatid cyst is still common in Nepal. Now we see more in younger age group.

Prognosis of surgery in younger age group is good. In our Study most of the Pulmonary Hydatid Cysts were large but unilocator.

\section{References}

1 Schantz PM : Epidemiology of Cystic Echinococosis G lobal distribution \& Pattern of Transmission, Proceeding of National Seminar on Echinococosis, Kathmandu, Nepal 1996

2 Joshi $A B$, Joshi DD, Schantz PM etal, Epidemiological Assessment of Echinococosis in Nepal Proceedings of National Seminar on Echinococosis Kathmandu, Nepal 1996

3 Robert W. Tohan, Echinococcosis E-Medicine. J an 22, 2009

4 Harton, $\mathrm{C}$ hemotherapy of E chinococcus infection in Man with Albendazole, Pharmacopia Martin Dale 1993

5 Rajbhandary G.L., Hydatid Cysts complete resolution following Albendazole J.Nep. Med. Assoc. 1995.33,131-132

6 Gizzberg E. Pulmonary Hydatid Cyst. Robs Smith's Operative Surgery Thoracic Surgery J ackson J W, Cooper DKC, Butter Worth, London 1986, $194-203$

7 Rajbhandary G.L. Surgical Experience with Hydatid Cysts of Lung \& Liver. J.Society of Surgeons of Nepal 1998 - Vol 1, 13 - 15

8 Ayten A. Yten Kayi Cangir Srugical Treatment of Pulmonary Hydatid Cysts in Children J ournal of Pead. Surgery. 2001, Vol 36 Issue 6 Page (917 - 920).

9 WHO Informal working group on Echinococosis 2003. 3 grouping of Echinocococus Cyst.

10 Keramidas DC, Passalides AG, Soutis M. Hydatidosis Management in Children: Depend on Anatomical location for Treatment International Association of Hydatology. News letter of Hydatidosis 1997 is. 15

11 WUM, J hag LW 2 Hutt, Qian Z-X Surgical Treatment of Thoracic Hydatidosis Review of 1230 Cases. Chinese Medical Journal 2005: $118,1665$. 